\title{
Structural and Optical Properties of Mg Doped ZnO Thin Films Deposited by DC Magnetron Sputtering
}

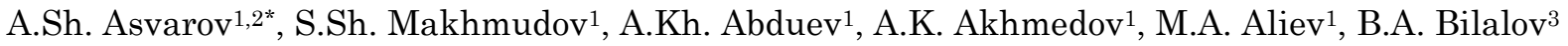 \\ 1 Institute of Physics, Dagestan Scientific Center, Russian Academy of Sciences, 94, Yaragskogo st., 367003 \\ Makhachkala, Russia \\ 2 Dagestan Scientific Center, Russian Academy of Sciences, Analytical Center for Collective Use, 45, Gadjieva st., \\ 367025 Makhachkala, Russia \\ ${ }^{3}$ Dagestan State Technical University, 70, I. Shamil st., 367015 Makhachkala, Russia
}

\begin{abstract}
(Received 15 August 2016; revised manuscript received 23 November 2016; published online 30 November 2016)
This paper reports the growth and characterization of transparent magnesium doped zinc oxide (ZnO:Mg) thin films prepared on glass substrates by dc magnetron sputtering. The effects of the $\mathrm{Mg}$ concentrations (0, 1 and 5 at \%) and working gas compositions (pure $\mathrm{Ar}$ and $\mathrm{Ar}-\mathrm{O}_{2}$ mixture) on the structural and optical properties of the $\mathrm{ZnO}: \mathrm{Mg}$ thin films were investigated. The experiment results showed that the $\mathrm{ZnO}$ and $\mathrm{ZnO}: \mathrm{Mg}$ thin films are polycrystalline with a hexagonal wurtzite structure exhibiting a preferred (002) crystal plane orientation. The results indicated that the crystallinity of $\mathrm{ZnO}: \mathrm{Mg}$ thin films was significantly affected by both $\mathrm{Mg}$-doping and the woking gas composition. Optical studies revealed that the optical band gap increases with $\mathrm{Mg}$ concentration.
\end{abstract}

Keywords: $\mathrm{ZnO}: \mathrm{Mg}$ thin film, Magnetron sputtering, Structural parameters, Transmittance, Band gap.

\section{INTRODUCTION}

Magnesium doped zinc oxide has attracted attention of researchers worldwide due to its wide range of applications in numerous fields. The similarity of the properties between $\mathrm{ZnO}: \mathrm{Mg}$ and more expensive $\mathrm{GaN}$ makes $\mathrm{ZnO}: \mathrm{Mg}$ one of the most promising materials for the photonic devices in the ultraviolet range [1]. In high efficiency CIGS-based solar cells, $\mathrm{ZnO}: \mathrm{Mg}$ is regarded as a promising buffer layer for the replacement of toxic CdS [2]. The $\mathrm{ZnO}: \mathrm{Mg}$ thin film has been used as an active layer for thin film transistors [3] and white light emitting diodes [4]. Furthermore, the recently discovered ferroelectric behaviour in the $\mathrm{ZnO}: \mathrm{Mg}$ thin film makes it useful for future ferroelectric random access memory device application [5].

The $\mathrm{ZnO}: \mathrm{Mg}$ thin films can be synthesized using various techniques such as molecular beam epitaxy [6], pulsed laser deposition [7], sputtering [8], electron beam evaporation [9], metal organic chemical vapor deposition [10] and sol-gel method [11]. Among these techniques, in the technological point of view, magnetron sputtering offers many advantages like high reproducibility, "scaled up" simplicity, moderate process temperature, good films' adhesion etc. Thus possibility for tuning of optical and electrical properties of the $\mathrm{ZnO}$ by doping $\mathrm{Mg}$ impurity in wide range and breadth of potential fields of application of $\mathrm{ZnO}: \mathrm{Mg}$ prompt to study extensively effects of process conditions for various thin film techniques on the functional properties of this material.

In this study, we present the results regarding the effects of $\mathrm{Mg}$ doping level and working gas composition on the structural and optical properties $\mathrm{ZnO}: \mathrm{Mg}$ thin films fabricated on glass substrates by dc magnetron sputtering of ceramic targets.

\section{EXPERIMENTAL}

\subsection{Preparation of Samples}

The investigated thin films were deposited on glass substrates by dc magnetron sputtering from $5 \mathrm{~cm}$ diameter $\mathrm{ZnO}$ targets containing 0,1 and $5 \mathrm{~mol} \% \mathrm{MgO}$ using magnetron sputteing system (VUP-4, USSR). The targets were prepared using a conventional solid-state reaction method. In order to conductivity, the target were post-annealed in $\mathrm{H}_{2}$ gas ambient at $600{ }^{\circ} \mathrm{C}$ during 30 min using a tube furnace. The glass substrates (borosilicate glass D 263, Russia) were ultrasonically cleaned in isopropanol and rinsed in deionized water before being introduced into the sputtering chamber. The chamber was evacuated to a base pressure of $5 \times 10$ ${ }^{3} \mathrm{~Pa}$, and the substrate was then heated to growth temperature of $300{ }^{\circ} \mathrm{C}$.

Two sets of the $\mathrm{ZnO}$ and $\mathrm{ZnO}: \mathrm{Mg}$ films were deposited in an inert ambient $(100 \% \mathrm{Ar})$ and a reactive gas ambient of $\mathrm{Ar}: \mathrm{O}_{2}(80: 20)$ at total sputtering pressure of $1 \mathrm{~Pa}$ at an applied power of $50 \mathrm{~W}$. High-purity argon and oxygen (purity $99.9 \%$ ) was used. The substrate to target distance was $7.5 \mathrm{~cm}$. The deposition time for all six samples was $60 \mathrm{~min}$.

\subsection{Characterization of Samples}

The deposited films were characterized for phase, crystallographic orientation and crystallinity using Xray diffraction measurement (XRD Empyrean, PANalytical B.V., Netherlands) in $\theta-2 \theta$ scan mode with $\mathrm{Cu} \mathrm{Ka}$ $(\lambda=0.1542 \mathrm{~nm})$. The tube of the diffractometer was operated at a current of $40 \mathrm{~mA}$ and a voltage of $40 \mathrm{KV}$. The scan range was set for $2 \theta$ of $28^{\circ}-78^{\circ}$ using a step size of $0.014^{\circ}$ with the time per step of 30 seconds. From the XRD diffraction patterns the main character-

\footnotetext{
*cht-if-ran@mail.ru
} 
istics of observed peaks such as their position, intensity, form and full width at half maxima (FWHM) was estimated by using HighScore Plus software.

UV-visible spectroscopy was utilized for studying the optical transparency of the deposited thin films. The transmission spectra ranging from 300-1100 nm were measured by using a UV-3600 spectrophotometer (Shimadzu, Japan). Data on the absorption edge of the transmission spectra were used to determine the optical bang gap by the Tauc method. At the same time, the thickness and the optical constants of the thin films were determined from the transmittance spectra too by utilising special PUMA software, based on the pointwise unconstrained minimization approach method [12]. Additional measurement of the film thickness for the several samples by profilometry (Model 130 Profilometer, Proton-MIET, Russia) confirmed sufficiently accuracy of the used optical method for determining the thickness of the $\mathrm{ZnO}$ thin films.

\section{RESULTS AND DISCUSSION}

Fig. 1 shows the evaluation of the growth rate for the $\mathrm{ZnO}: \mathrm{Mg}$ thin films deposited under the same sputtering power and time duration. This evaluation revealed that the growth rate is strongly dependent on the $\mathrm{Mg}$ doping level in the case of sputtering in pure Ar. The growth rate decreased from 17.5 to $9 \mathrm{~nm} / \mathrm{min}$ when the $\mathrm{Mg}$ content increases up to 5 at \%, that might be due to difference in sputtering efficiency for pure $\mathrm{ZnO}$ and $\mathrm{Mg}$-doped $\mathrm{ZnO}$ targets. Addition of the $\mathrm{O}_{2}$ to the working gas resulted naturally in a decrease in the growth rate to about $7 \mathrm{~nm} / \mathrm{min}$, however, in this case, the growth rate became insensitive to the composition of the sputtering target.

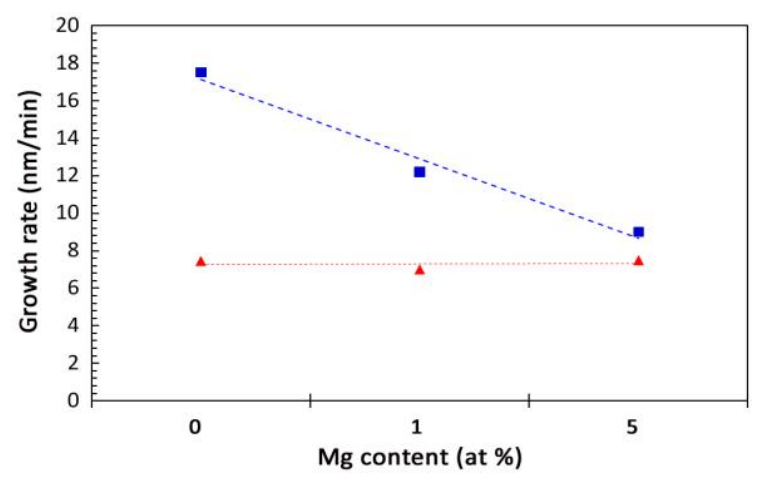

Fig. 1 - Dependence of growht rate of the thin films on $\mathrm{Mg}$ content for sputtering in pure $\mathrm{Ar}$ (squares) and $\mathrm{Ar}-\mathrm{O}_{2}$ mixture (triangles)

Fig. 2 presents XRD patterns of undoped $\mathrm{ZnO}$ and $\mathrm{ZnO}: \mathrm{Mg}$ thin films deposited on glass substrates in the inert ambient (100\% Ar) and the reactive gas ambient (Ar- $\mathrm{O}_{2}$ gas mixture). All the thin films show a strong preferred orientation: there is the dominant diffraction from $(00 l)$ planes of a hexagonal wurtzite structure $\mathrm{ZnO}$ indicating that crystal $c$-axis of the films is inclined to be perpendicular to the substrate surface.

The doping up to 5.0 at \% of $\mathrm{ZnO}$ thin films did not result in the formation of new phases related with $\mathrm{Mg}$, which means that the impurity does not change the wurtzite structure of $\mathrm{ZnO}$.
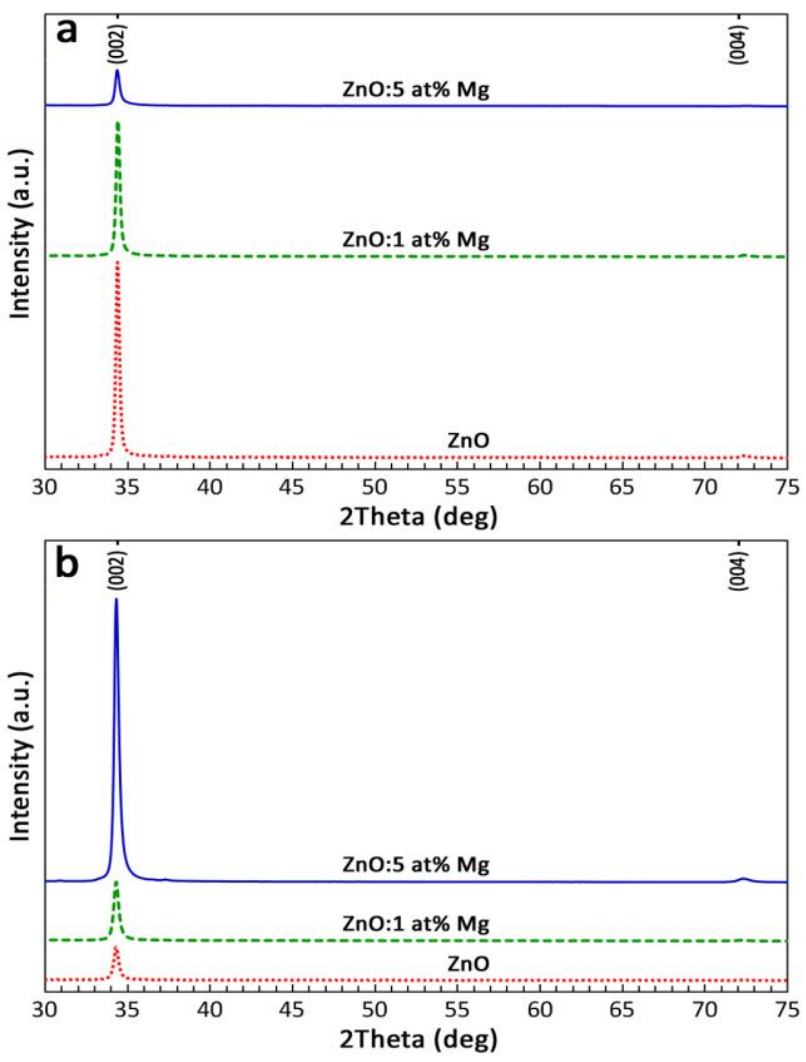

Fig. 2 - XRD spectra of $\mathrm{ZnO}$ and $\mathrm{ZnO}: \mathrm{Mg}$ thin films deposited in $\mathrm{Ar}$ (a) and in $\mathrm{Ar}-\mathrm{O}_{2}$ gas mixture (b)

The doping of $\mathrm{ZnO}$ by $\mathrm{Mg}$ changes the intensities of (002) peak, its position and FWHM. In the case of the sputtering in pure Ar (Fig. 2a) the intensity of (002) peak decreases, the peak shifts slightly to higher values of $2 \theta$, and the FWHM increases with increasing the doping level. This behavior indicates that the crystal quality of the films was deteriorated with higher $\mathrm{Mg}$ concentration in the $\mathrm{ZnO}$ crystal system.

Introducing oxygen into the working gas results in significant suppression of the (002) peak intensity and broadening of the peak for the undoped $\mathrm{ZnO}$ thin film (Fig. 2b). However, in this case the intensity of (002) peak increases and the FWHM decreases with increasing the doping level. It clearly indicates that crystal quality of the films deposited in Ar- $\mathrm{O}_{2}$ gas gas ambient get improved with increase in the $\mathrm{Mg}$ content.

The average crystalline size (the size of the coherently scattering domains) in the deposited $\mathrm{ZnO}: \mathrm{Mg}$ thin films was evaluated by using the Scherrer's formula,

$$
D=0.94 \lambda /(\beta \sin \theta),
$$

where $D$ is average crystalline size of crystal, $\lambda$ is the wavelength of the X-ray source used, $\beta$ is the FWHM of the (002) peak and $\theta$ is the angle of the peak.

Also the lattice parameter $c$ of the wurtzite structure $\mathrm{ZnO}$ were calculated, according to the formula for a hexagonal structure

$$
c=2 d_{002}=\lambda / \sin \theta
$$

The calculated average crystalline size and lattice 
parameter $c$ are plotted in Fig. 3. As can be seen from the Fig. 3a, the doping of $\mathrm{ZnO}$ thin films deposited in the $\mathrm{Ar}$ ambient changes the crystalline size from 39 to $31 \mathrm{~nm}$, i.e. $\mathrm{Mg}$ impurity in this case plays a role of the crystallite growth inhibitor.
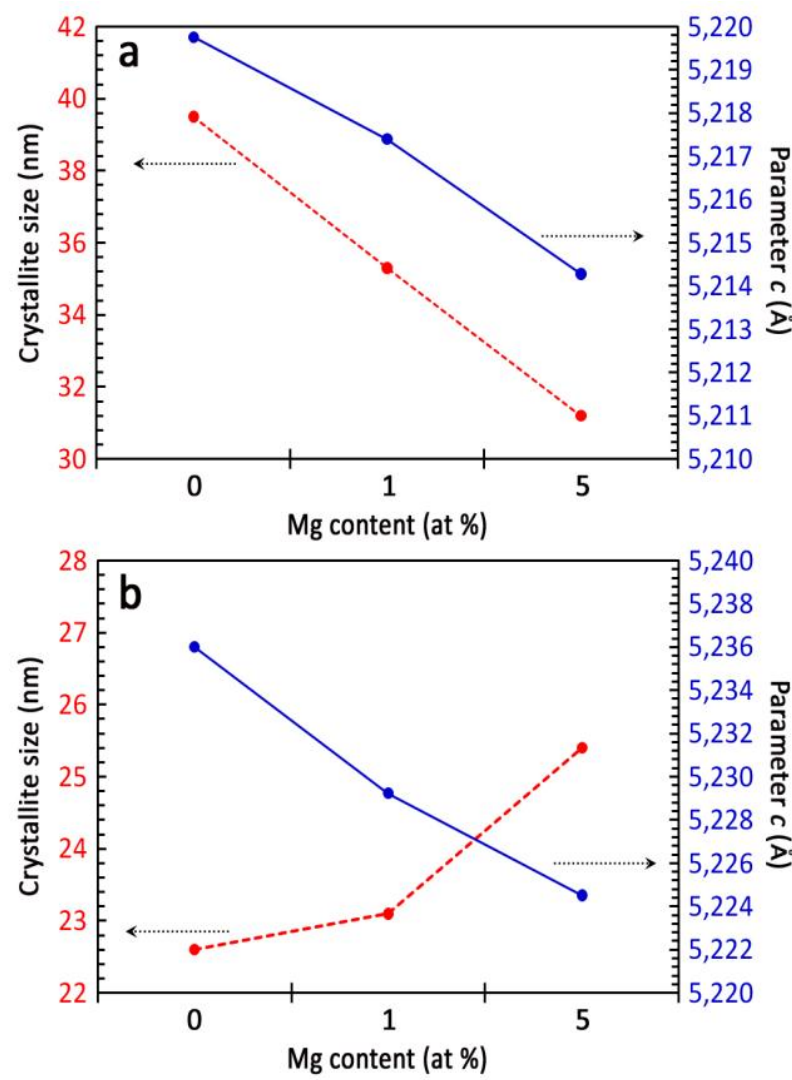

Fig. 3 - Average crystalline size and lattice parameter $c$ of $\mathrm{ZnO}$ and $\mathrm{ZnO}: \mathrm{Mg}$ thin films deposited in $\mathrm{Ar}$ (a) and in $\mathrm{Ar}-\mathrm{O}_{2}$ gas mixture (b)

Further, it can also be seen that the introduction of $\mathrm{O}_{2}$ into the working gas also suppresses the growth of $\mathrm{ZnO}$ crystallites by comparing the data for the undoped $\mathrm{ZnO}$ films - the crystalline size decreased from 39 to $22.5 \mathrm{~nm}$ (Fig. 3a and 3b). However, for the layers deposited in the Ar- $\mathrm{O}_{2}$ ambient the crystallite size increases with increasing magnesium content up to 5 at \% (Fig. 3b), i.e. $\mathrm{Mg}$ impurity improves the crystallinity of $\mathrm{ZnO}$ thin films deposited in the the reactive gas ambient.

Meanwhile, it was clear from Fig. 3 that the calculated lattice parameter $c$ for all undoped and $\mathrm{Mg}$ doped $\mathrm{ZnO}$ thin films has lager values compared with the bulk $\mathrm{ZnO}\left(c_{0}=5.205 \AA\right)$, implying by some positive strain of $\mathrm{ZnO}$ films which indicated a compressive stress in the films [8].

Comparing Fig. 3a and 3b, it can be concluded that the films deposited in the $\mathrm{Ar}-\mathrm{O}_{2}$ ambient are more strained. However, in both cases, the lattice constant $c$ decreased with increasing of the $\mathrm{Mg}$ content. As has been reported previously, the presence of interstitial oxygen had an expansive effect on the lattice, which resulted in the compressive strain, occurring along the $c$-axis [13]. Therefore, the O-rich sputtering condition, that could promote occurrence of interstitial defects, are responsible for the presence of large stress in the $\mathrm{ZnO}: \mathrm{Mg}$ thin films. In the same time, the incorporation of $\mathrm{Mg}$ in $\mathrm{ZnO}$ lattice site contributed to reduction of the compressive stress [7, 14].

Optical transmittance spectra of the $\mathrm{ZnO}: \mathrm{Mg}$ thin films prepared with different $\mathrm{Mg}$ concentration in the wavelength range from 300 to $1100 \mathrm{~nm}$ are shown in Fig. 4.

Thin-film interference was observed in all spectra. The number and the magnitude of interference extrema depended on the film thickness, optical constants of the films and the smoothness of the film interfaces. Spectrophotometric measurements of the $\mathrm{ZnO}: \mathrm{Mg}$ thin films, deposited in Ar ambient, revealed that the transmittance in the visible range was diminished with the drop in $\mathrm{Mg}$ content (Fig. 4a). However, in addition to the contribution of doping, this should be associated to the increased surface roughness too. The thicknesses of undoped $\mathrm{ZnO}, \mathrm{ZnO}: 1 \mathrm{at} \% \mathrm{Mg}$ and $\mathrm{ZnO}: 5$ at\% $\mathrm{Mg}$ thin films were 1050, 730 and $540 \mathrm{~nm}$, respectively. It is known for $\mathrm{ZnO}$-based films that the roughness tends to increase with rise the film thickness [15]. The roughness of the film affects the transparency due to scattering of incident light.
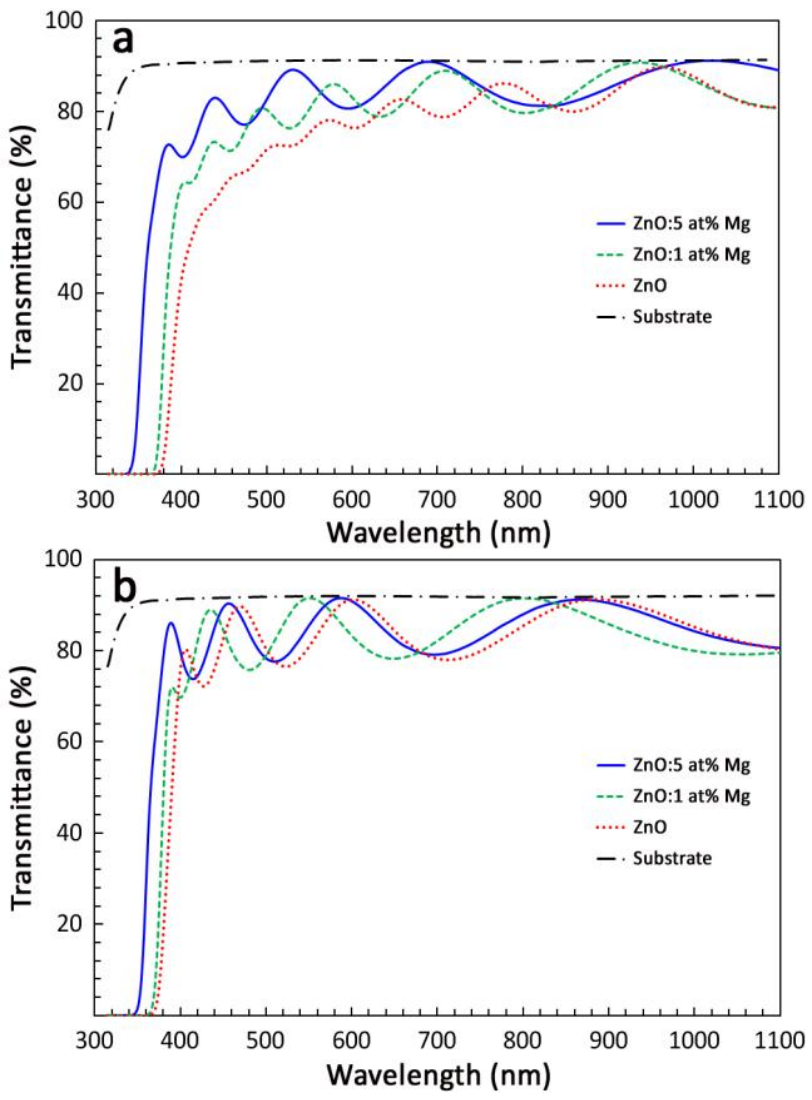

Fig. 4 - Optical transmittance spectra of $\mathrm{ZnO}$ and $\mathrm{ZnO}: \mathrm{Mg}$ thin films deposited in $\mathrm{Ar}$ (a) and in $\mathrm{Ar}-\mathrm{O}_{2}$ gas mixture (b)

In turn, in the case of sputtering in the Ar- $\mathrm{O}_{2}$ ambient (Fig. 4b), when the films had approximately same thickness of $420-450 \mathrm{~nm}$, we found no significant differences in the transparence of the films with varying $\mathrm{Mg}$ concentrations for the spectral range of 400-1100 $\mathrm{nm}$. Main effect of Mg impurity on the optical transmittance of $\mathrm{ZnO}$ was that the absorption edge shifts to a 
shorter wavelength.

In order to calculate the direct optical band gap of the deposited $\mathrm{ZnO}: \mathrm{Mg}$ films, the Tauc relationship was used. In direct transition semiconductors, such as $\mathrm{ZnO}$, the optical absorption coefficient $\alpha$ and the optical band gap $E_{g}$ are related by

$$
(\alpha h v)^{2}=B\left(h v-E_{g}\right),
$$

where $h v$ and $B$ are the photonic energy and constant, respectively. Since $E_{g}=h v$ when $(\alpha h v)^{2}=0$, an extrapolation of the linear region of the plot of $(\alpha h v)^{2}$ versus photon energy $(h v)$ on the $h v$-axis gives the value of the optical bandgap $E_{g}$ (Fig. 5).
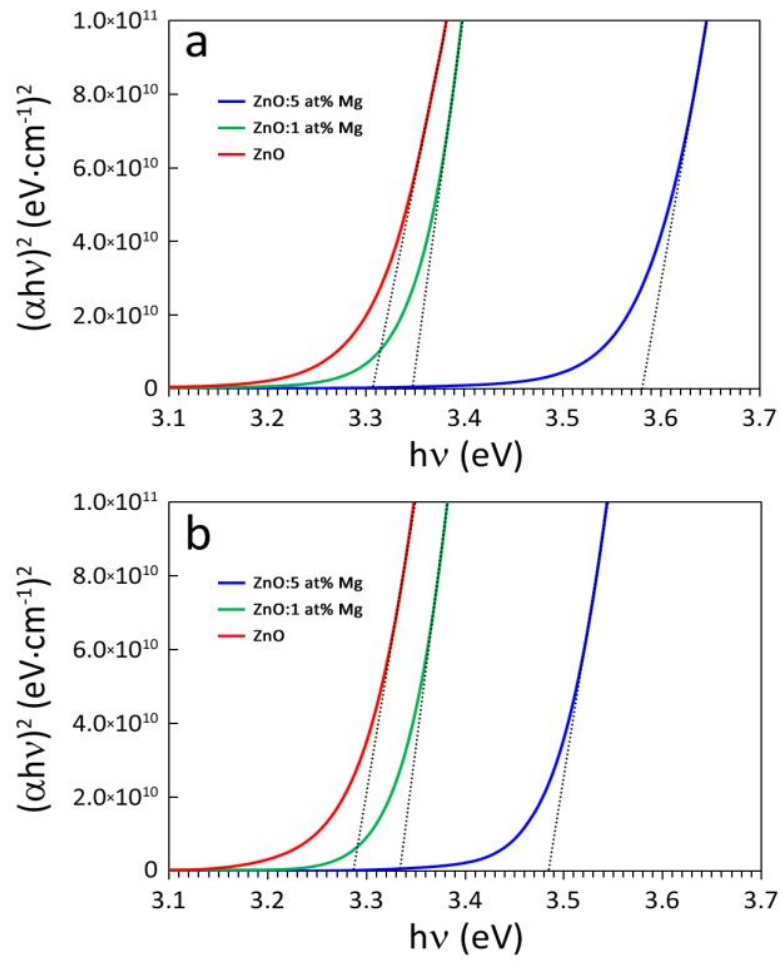

Fig. 5 - Plot of $(\alpha h v) 2$ versus hv of undoped $\mathrm{ZnO}$ and $\mathrm{ZnO}: \mathrm{Mg}$ films deposited in $\mathrm{Ar}$ (a) and in $\mathrm{Ar}-\mathrm{O}_{2}$ gas mixture (b)

The calculated optical band gap of the $\mathrm{ZnO}$, $\mathrm{ZnO}: 1$ at \% $\mathrm{Mg}$ and $\mathrm{ZnO}: 5$ at\% $\mathrm{Mg}$ thin films, deposited

\section{REFERENCES}

1. P. Zu, Z.K. Tang, G.K.L. Wong, M. Kawasaki, A. Ohtomo, H. Koinuma, Y. Segawa, Solid State Commun. 103, 459 (1997).

2. I. Lauermann, Ch. Loreck, A. Grimm, R. Klenk, H. Mönig, M.Ch. Lux-Steiner, Ch.-H. Fischer, S. Visbeck, T.P. Niesen, Thin Solid Films 515, 6015 (2007).

3. J.S. Wrench, I.F. Brunell, P.R. Chalker, J. Jin, A. Shaw, I. Mitrovic, S. Hall, Appl. Phys. Lett. 105, 202109 (2014).

4. X. Dong, H. Wang, J. Wang, W. Zhao, L. Zhao, Zh. Shi, J. Phys.: Conf. Ser. 276, 012093 (2011).

5. L. Shi, D. Shang, J. Sun, B. Shen, Appl. Phys. Express 2, 101602 (2009).

6. H.Q. Huang, F.J. Liu, J. Sun, J.W. Zhao, Z.F. Hu, Z.J. Li, X.Q. Zhang, Y.S. Wang, Appl. Surf. Sci. 257, 10721 (2011)

7. F.K. Shan, B.I. Kim, G.X. Liu, Z.F. Liu, J.Y. Sohn, W.J. Lee, B.C. Shin and Y.S. Yu, J. Appl. Phys. 95, 4772 (2004).

8. H. Chen, J. Ding, Sh. Ma, Physica E 42, 1478 (2010). in the $\mathrm{Ar}$ ambient, are $3.31,3.35$ and $3.58 \mathrm{eV}$, respectively (Fig. 5a). In turn, when we use the $\mathrm{Ar}-\mathrm{O}_{2}$ gas mixture as the working gas, the optical band gap of the films showed some "red shift" - the calculated optical band gap energies determined from the obtained absorption spectra are $3.29,3.33$ and $3.48 \mathrm{eV}$ for the pure $\mathrm{ZnO}, 1$ and 5 at. $\% \mathrm{Mg}$ doped $\mathrm{ZnO}$ thin films, respectively.

In both cases the band gap energy of $\mathrm{Mg}$ doped $\mathrm{ZnO}$ thin film increases almost linearly with increasing dopant concentration, that is in accordance with Vagard's law.

We believe that the Eg widening phenomenon is due to the fact that the incorporation of $\mathrm{Mg}$ in lattice sites of the $\mathrm{ZnO}$ crystal lattice can induce a decrease in $\mathrm{Zn} 4 \mathrm{~s}$ states at the bottom of the conduction band, which leads to a shift of the conduction band and a widening of the band gap [16]. The detected "red shift" for $\mathrm{Ar}-\mathrm{O}_{2}$ reactive gas ambient might be related with the fact that $\mathrm{O}_{2}$ plays a notable role in suppression of the incorporation of $\mathrm{Mg}$ atoms in the $\mathrm{ZnO}$ crystal lattice.

\section{CONCLUSIONS}

In this work, $\mathrm{Mg}$ doped $\mathrm{ZnO}$ thin films were successfully prepared on glass substrate by dc magnetron sputtering method. The results established the dependence of $\mathrm{Mg}$ dopant concentration and working gas composition on the structural and optical properties of the $\mathrm{ZnO}: \mathrm{Mg}$ thin films. XRD measurements revealed that crystallinity of the $\mathrm{ZnO}: \mathrm{Mg}$ was significantly affected by $\mathrm{Mg}$ doping level and the working gas ambient. Further, it is shown that the composition of the working gas has a greater influence on the transmittance of $\mathrm{ZnO}: \mathrm{Mg}$ thin films in the visible region, while the doping allows to effectively tune the bang gap of $\mathrm{ZnO}: \mathrm{Mg}$ thin films. It is revealed that the band gap energy of $\mathrm{ZnO}: \mathrm{Mg}$ thin film increases almost linearly with increasing dopant concentration.

\section{AKNOWLEDGEMENTS}

This work was partially funded by RFBR according to the research projects № 16-07-00503 and № 16-0700469 .

9. P. Yu, H.Z. Wu, T.N. Xu, D.J. Qiu , G.J. Hu, N. Dai, J. Cryst. Growth 310, 336 (2008).

10. Z. Duan, A. Du Pasquier, Y. Lu, Y. Xu, E. Garfunkel, Sol. Energ. Mater. Sol. C. 96, 292 (2012).

11. M. Caglar, J. Wu, K. Li, Y. Caglar, S. Ilican, D. Xue, Mater. Res. Bull. 45, 284 (2010).

12. E.G. Birgin, I. Chambouleyron, J.M. Martinez, J. Comput. Phys. 151, 862 (1999).

13. L.W. Wang, L.J. Meng, V. Teixeira, S.G. Song, Z. Xu, X.R. Xu, Thin Solid Films 517, 3721 (2009).

14. A. Kaushal, D. Kaur, Sol. Energ. Mater. Sol. C. 93, 193 (2009).

15. A. Abduev, A. Akmedov, A. Asvarov, A. Chiolerio, Plasma Process. Polym. 12, 725 (2015).

16. X.D. Zhang, M.L. Guo, C.L. Liu, L.A. Zhang, W.Y. Zhang, Y.Q. Ding, Q. Wu, X. Feng, Eur. Phys. J. B. Condens. Matter Complex Syst. 62, 417 (2008). 